\section{Liaison psychiatry or psychological medicine?}

\author{
GEOFFREY G. LLOYD and RICHARD A. MAYOU
}

Liaison psychiatry has been recognised in many countries as a special interest or sub-speciality of psychiatry concerned with the management of general hospital patients with psychological problems. However, despite increasing awareness of the emotional and behavioural aspects of illness, it has yet to achieve substantial influence within psychiatry and, more importantly, has had only modest effects on the delivery of medical care by physicians and other specialists. Recognition of its potential by planners and commissioners has been disappointing. Regrettably, in the UK and elsewhere, recent changes in the organisation of health care could hinder its development. This paper argues that in order to make substantial progress there is a compelling need to solve a fundamental obstacle - the separation between psychiatric and general medical care. This requires:

(a) convincing the psychiatric profession that consultation-liaison is a distinct sub-speciality;

(b) continuing efforts by liaison psychiatrists to define their special expertise and to demonstrate that their services are effective and acceptable to medical colleagues and to patients;

(c) persuading those who organise health care that liaison psychiatry services need to be provided and administered as an integral component of comprehensive medical care.

\section{THE PROBLEM \\ AND THE EVIDENCE}

We believe that the continuing problems for liaison psychiatry result from a failure to resolve long-standing issues about the extent to which psychiatry is an integral part of medicine. Modern psychiatry has evolved from an amalgamation of two historically separate types of practice: the care of psychotic patients housed in large asylums, and the treatment of those with 'nervous disorder' treated mainly by physicians or neurologists in general hospitals. The resultant incorporation of psychiatry into the mainstream of medicine did much to reduce the stigma and increase awareness of psychiatric illness. It also enabled psychiatrists to make a more effective contribution to care in general hospitals and to medical education.

This integration is now under threat from potentially harmful administrative changes. The National Service Framework (NSF) for Mental Health in England recommended that mental health services should be provided by single-speciality mental health trusts, particularly for inner cities and metropolitan areas (Department of Health, 1999). Established by decree, with inadequate debate, little or no attempt at evaluation and scant resistance from the psychiatric profession, these mental health trusts threaten to repeat the mistakes of their 19th-century predecessors. This divisive development is likely to perpetuate the stigma of mental illness. It runs counter to the view that the distinction between physical and mental illness is conceptually flawed (Kendell, 2001).

Solutions to the problems confronting liaison psychiatry depend in part upon a wider understanding of the evidence base. Psychological factors are major determinants of the presentation and consequences of physical illness and medically unexplained symptoms that make up a large part of clinical practice in both primary and secondary care. There is a high prevalence of diagnosable psychiatric disorder in inpatient and out-patient populations, which is accompanied by considerable disability and increased use of resources. Psychiatric disorders are also conspicuous in accident and emergency departments. In some cities these departments have become the first port of call for people with psychiatric illness in a crisis (Johnson \& Thornicroft, 1995). Overall, the general hospital is a major portal of entry to mental health services (Gater \& Goldberg, 1991).

Although morbidity is extensive, psychiatric and psychological problems are frequently not recognised; even if recognised, they are often not treated. Patients' inability to find acceptable help for their symptoms has been accompanied by a substantial growth of complementary and alternative medicine often with the tacit, and sometimes explicit, support of orthodox health care.

In contrast to the unsatisfactory provision of psychiatric care there is a substantial body of evidence regarding the benefits of treatment. Antidepressant medication is effective in treating patients whose depression accompanies physical illness (Gill \& Hatcher, 2001) and also patients with unexplained (functional) symptoms (O'Malley et al, 1999). Psychological treatments have proved effective in treating functional syndromes (Kroenke \& Swindle, 2000) such as chronic fatigue, irritable bowel syndrome and unexplained chest pain.

There is also evidence of the effectiveness of programmes directed to specific groups, for example women with postnatal depression (Appleby et al, 1997) and patients presenting following episodes of deliberate self-harm (Guthrie et al, 2001). There is increasing awareness of the effectiveness of psychological and behavioural interventions in the routine management of chronic physical illness. This has resulted in the development of primary care protocols based on the principles of collaborative self-help with patients and stepped care (i.e. successive steps of treatment intensity according to individual need). Whereas all care is based on behavioural principles, specialist psychological and psychiatric assessment and treatment should be available for a minority (Von Korff et al, 1997).

\section{THE AIMS AND ROLE OF LIAISON PSYCHIATRY}

Liaison psychiatry was originally directed to general hospital in-patients with conspicuous psychiatric problems. However, recognition of the extent of psychiatric illness in medical patients and the development of effective treatments have broadened its scope. Changes in health care delivery, particularly the reduction of inpatient duration and the development of special out-patient and day-patient treatment, have enabled many liaison psychiatry 
services to be carried out in out-patient clinics. These need to be located in general hospitals, are often multi-disciplinary and work best alongside the medical departments to which patients are referred originally.

It is important to distinguish these liaison roles from the psychiatric assessment of patients seen in accident and emergency departments following deliberate self-harm or an acute psychotic episode. These patients continue to make up a major part of the workload of many liaison psychiatrists in the UK but they are more widely seen as the responsibility of communitybased crisis intervention teams. In practice, arrangements vary from hospital to hospital according to local patterns of health care. This is a crucial interface area between liaison and community teams and primary care. It is essential that relative responsibilities are agreed and understood in every hospital.

Liaison psychiatrists acquire particular skills in the assessment and management of patients with psychiatric and physical comorbidity and with complicated functional somatic symptoms. Special training and experience are required to assess the complex range of psychiatric problems in medical patients. In the UK this has been recognised by the General Medical Council, which now endorses liaison psychiatry as a sub-speciality within general psychiatry. In the USA the American Board of Psychiatry and Neurology has supported an application that psychosomatic medicine be recognised as a psychiatric sub-speciality with a view to making a submission to the American Board of Medical Specialties to issue a sub-speciality certificate (Lyketsos, 2002).

\section{RELATIONSHIP WITH PSYCHIATRY AND MEDICINE}

Many psychiatrists do not fully understand the role and potential of liaison psychiatry. They have focused on community-based treatment of patients with chronic psychotic disorders and underestimated the distress and disability of more common problems. In doing so they have enabled planners to make the same mistakes. Thus the NSF for Mental Health made no reference to liaison psychiatry other than to the management of deliberate self-harm. In contrast, the Scottish Executive's Our National Health (Scottish Executive Health Department, 2000) specifically

GEOFFREY G. LLOYD, FRCP, FRCPsych, Royal Free Hospital, London, UK; RICHARD A. MAYOU, FRCP, FRCPsych, University of Oxford, Warneford Hospital, Oxford, UK

Correspondence: Dr G. Lloyd, Department of Psychiatry, Royal Free Hospital, Pond Street, London NW3 2QG, UK. E-mail: Geoffrey.Lloyd@rfh.nthames.nhs.uk

acknowledged the evidence to support the role of liaison psychiatry and made a commitment to foster its further development.

Research funding bodies and many academic psychiatrists view the psychological problems of medical patients as being of minor interest, less worthy of financial support for research than neuroscience. This indifference by psychiatry itself is doing at least as much harm as the lack of understanding of previous generations of physicians. Overcoming this apathy among our direct colleagues is a challenge that liaison psychiatry must face.

Difficulties within psychiatry are in contrast to the encouragement that comes from physicians and surgeons who are increasingly aware of the psychiatric problems with which they have to deal, particularly in the growing number of patients with chronic illnesses and long-term disabilities. The NHS Cancer Plan (Department of Health, 2002) and the NSF for Older People (Department of Health, 2001) both stressed the importance of access to psychological care and psychiatric services. A joint report of the Royal College of Physicians \& Royal College of Psychiatrists (1995) recommended that purchasers of health care should not commission acute services which failed to make adequate provisions for the psychosocial needs in the general hospital. The report advocated the establishment of a liaison psychiatry service in all general hospitals (funded by acute hospital trusts but managed within mental health trusts), with extra provision being made in teaching hospitals with large tertiary referral services. These recommendations are gradually being implemented but many general hospitals continue to have an extremely rudimentary psychiatric service.

\section{THE WAY FORWARD}

Liaison psychiatry has come a long way since services were first established. It still has much to do to convince medical and psychiatric colleagues of its effectiveness and the need for administrative change. It needs also to make itself more acceptable to medical colleagues and to patients. Administrative changes are essential. We regret the separation of mental health services from the mainstream of medical care. We believe that liaison psychiatry should be funded and managed alongside other medical specialities within acute general hospital trusts. It should stress its successes in managing the common but complicated problems in general medical practice rather than confine itself to psychiatric emergencies in accident and emergency departments.

The present difficulties have arisen not only from the lack of interest of most psychiatrists and health providers but also from failures of liaison psychiatry to define and explain its role in an acceptable manner that will be persuasive to patients, colleagues and health care commissioners. Plans must be explained in a language that will be understood by patients and by nonpsychiatrist doctors. This must mean that we abandon terms that have little real meaning but tend to perpetuate the separation of mind and body and the belief that psychologically determined problems are undeserving of treatment. Terms such as somatisation and somatoform disorder manage to be both conceptually confusing and unacceptable to patients. Even the term liaison psychiatry is confusing and is used too widely to be meaningful. We propose that psychological medicine would be the best term for the type of work practised by psychiatrists based in general hospitals. There is now ample evidence for the effectiveness of psychiatric interventions in general hospital patients. This evidence provides a platform to justify an expansion of services, a platform on which service development plans can be based. Adequate funding for these services should be an essential component of all contracts between acute hospital trusts and their commissioners.

\section{DECLARATION OF INTEREST}

None.

\section{REFERENCES}

Appleby, L., Warner, R., Whitton, A., et al (1997) A controlled trial of fluoxetine and cognitive-behavioural 
counselling in the treatment of postnatal depression. BMJ, 314, 932-936.

Department of Health (1999) A National Service Framework for Mental Health. London: Department of Health.

- (200I) A National Service Framework for Older People. London: Department of Health.

- (2002) The NHS Cancer Plan. London: Department of Health.

Gater, R. \& Goldberg, D. (1991) Pathways to psychiatric care in South Manchester. British Journal of Psychiatry, 159, 90-96.

Gill, D. \& Hatcher, S. (200I) Anti-depressants for depression in medical illness. Cochrane Library, issue 4. Oxford: Update Software.
Guthrie, E., Kapur, N., Mackway-Jones, K., et a (200I) Randomised controlled trial of brief psychological intervention after deliberate self poisoning. $B M J, \mathbf{3 2 3}$, 135-138.

Johnson, S. \& Thornicroft, G. (1995) Emergency psychiatric services in England and Wales. BMJ, 3II, 287-288.

Kendell, R. E. (200I) The distinction between mental and physical illness. British Journal of Psychiatry, 178, 490-493.

Kroenke, K. \& Swindle, R. (2000) Cognitive behavioural therapy for somatization and symptom syndromes: a critical review of controlled clinical trials. Psychotherapy and Psychosomatics, 69, 205-215.

Lyketsos, C. G. (2002) Psychosomatic medicine: the emergence of a psychiatric subspecialty? Academy of Psychosomatic Medicine: Academy Newsletter, January.
O'Malley, P. G., Jackson, J. L., Santoro, J., et al (1999) Antidepressant therapy for unexplained symptoms and symptom syndromes. Journal of Family Practice, 48, 980-990.

Royal College of Physicians \& Royal College of Psychiatrists (1995) The Psychological Care of Medical Patients. A Guide for Purchasers. Council Report CR38. London: Royal College of Physicians of London \& Royal College of Psychiatrists.

Scottish Executive Health Department (2000) Our National Health: a Plan for Action, a Plan for Change. Edinburgh: Stationery Office.

Von Korff, M., Gruman, J., Schaeffer, J., et al (1997) Collaborative management of chronic illness. Annals of Internal Medicine, 127, 1097-1102. 